\title{
PESCA, POLÍTICA E PARENTESCO: ORGANIZAÇÕES PRODUTIVAS E PROCESSOS DE FAMILIARIZAÇÃO EM COLETIVOS DE PESCAS POTIGUARES
}

\author{
FISHING, POLITICS AND KINSHIP: \\ PRODUCTIVE ORGANIZATIONS AND \\ FAMILIARIZATION PROCESSES IN \\ POTIGUAR FISHERIES COLLECTIVES
}

Paulo Gomes de Almeida Filho

pfilhoantropologo@hotmail.com

Doutorando em Antropologia Social (PPGAS/UFRN) Pesquisador colaborador do grupo ETAPA -

Etnologia, Tradição, Ambientes e Pesca Artesanal

Orcid: https://orcid.org/0000-0002-1923-2317

\section{RESUMO}

A proposta deste artigo é discutir o papel conferido ao parentesco por coletivos de pesca artesanais e industriais do litoral potiguar. Faço isso através dos dados coletados em pesquisas antropológicas realizadas ao longo de dez anos junto a diferentes grupos. Tomando o parentesco enquanto um símbolo cultural pelo qual os grupos estudados elaboram uma identidade pescadora, na primeira parte da discussão, mostrarei como o parentesco é construído nesse universo social e a maneira como ele estrutura a organização produtiva. Na segunda parte, volto minha atenção ao conflito envolvendo as organizações políticas da pesca em São Miguel do Gostoso, que resultou na criação de uma Associação de pescadores mais afinada à organização política tradicional onde as relações de parentesco são centrais.

Palavras-chaves: Coletivos pesqueiros. Organização política. Parentesco.

\begin{abstract}
The purpose of this article is to discuss the role of kinship in artisanal and industrial fishing communities on the Potiguar coast. I do this through the data collected in anthropological research carried out over almost 10 years with different groups. Taking kinship as a cultural symbol by which the studied groups elaborate a fishery identity, in the first part of the discussion, I will show how kinship is constructed in this social universe and how it structures the productive organization. In the second part, I turn my attention to the conflict involving the political organizations of the fishing in São Miguel do Gostoso, that resulted in the creation of an Association of fishermen more attuned to the traditional political organization where the relations of kinship are central.
\end{abstract}

Keywords: Fishing collectives. Political organization. Kinship. 


\section{INTRODUÇÃO}

Ao longo de dez anos de pesquisas etnográficas junto a diferentes coletivos pesqueiros espraiados pelo litoral potiguar, dados sobre diferentes aspectos da vida sociocultural desse segmento foram sendo acumulados. Hoje percebo a oportunidade de refletir à luz do conhecimento antropológico sobre o papel conferido às relações de parentesco pelos grupos estudados.

Os estudos sobre as relações de parentesco estão presentes na Antropologia desde a sua origem em meados do século XIX. Na perspectiva do evolucionismo social, a matéria era entendida como um dos elementos importantes para a classificação em estágios de desenvolvimento das sociedades "primitivas", até então consideradas objeto de estudo da disciplina. A abordagem estrutural-funcionalista atribuía ao parentesco o papel de espinha dorsal na organização social das sociedades estudadas, cujo teórico baixo grau de complexidade levava a sua mistura com outras esferas da vida nativa, tais como a política, os rituais, os sistemas de crença, os processos técnicos, a economia etc. Nesse momento, a genealogia aparece como um método confiável para a compreensão dessas totalidades, conferindo o status de ciência à Antropologia. Em contrapartida, o estruturalismo francês, através de seu principal expoente, Claude Lévi-Strauss, opõe-se ao postulado estrutural-funcionalista britânico do estudo do parentesco através das linhas de descendência, propondo que a função do parentesco é a filiação, a troca matrimonial (a circulação de mulheres) entre grupos com a finalidade de estabelecer alianças. Aqui o parentesco aparece como um importante ordenador do mundo, através das regras de filiação. Lévi-Strauss afirma que o tabu do incesto é um princípio universal - embora admita que as definições de incesto sejam culturalmente variáveis - e marca o limiar entre natureza e cultura (BESTARD, 1998; WOORTMANN, 1977).

Até meados do século XX, o parentesco era uma agenda muito relevante na Antropologia, imprescindível para a compreensão das sociedades entendidas como de baixa complexidade. No entanto, a partir dos anos de 1960 foi gradativamente perdendo importância, primeiro, em virtude da complexificação disciplinar - o objeto da Antropologia passara por redefinição e o velho vocabulário evolucionista, com seus termos e divisões ("primitivos" e "civilizados"), fazia cada vez menos sentido -, onde outras esferas da vida social foram sendo elencadas como mais apropriadas para a compreensão dos grupos pesquisados. Outro motivo foram as críticas à natureza do parentesco, onde a mais famosa delas fora efetuada por Schneider. O autor defendia que o parentesco se tratava de um aparato teórico-conceitual antropológico que não tinha correspondente nos grupos estudados fora do ocidente (BESTARD, 1998). Segundo Woortmann (1977), para Schneider, o parentesco é um símbolo cultural que expressa um conjunto de relações, que ao contrário do que se imaginava, faziam mais sentido para os universos sociais dos quais os antropólogos pertenciam do que para as sociedades não-ocidentais as quais eles pesquisavam.

A consideração de que o parentesco havia sido superestimado, fora o deslocando da posição de pedra angular da Antropologia para uma posição secundária e marginal. Por outro lado, as críticas inauguradas por Schneider abrira precedentes nas décadas seguintes para a crítica feminista aos marcadores de sexo e gênero nos estudos clássicos de parentesco. É também a partir deste momento que as novas tecnologias reprodutivas suscitavam redefinições sobre as noções estabelecidas de família e parentesco, bem como, reflexão epistemológica mais ampla sobre os conceitos de natureza e cultura (BESTARD, 1998). Sobre a continuidade dos estudos antropológicos do parentesco, Almeida (2012) informa: 


\begin{abstract}
"A desconstrução de Schneider teve enorme sucesso, mas curiosamente ela não resultou no fim dos estudos de parentesco: em vez disso, ela marcou a divisão desse campo em estudos 'clássicos' de parentesco, e os 'novos estudos de parentesco'. American Kinship (1980), de David Schneider, bem como After Nature (1992), de Marilyn Strathern, são exemplos da direção tomada pelos 'novos estudos de parentesco', sendo uma marca distintiva deles a ausência completa de genealogias, terminologias de parentesco e de regras de casamento. Por outro lado, a tradição dos 'velhos estudos' continuou viva, mais na França e no Brasil do que na Inglaterra e nos EUA. Tanto na França como no Brasil, a continuidade dos estudos 'clássicos' ou morganianos de parentesco deve-se à sua redefinição da problemática feita por Lévi-Strauss, e de questões colocadas por Louis Dumont, Lounsbury e por Trautmann" (ALMEIDA, p. 318, 2012).
\end{abstract}

A breve recuperação da trajetória do parentesco enquanto campo de pesquisa na Antropologia me permite ressaltar a sua relevância neste estudo. Entendo que o enfoque antropológico sobre o parentesco, tal como formulado pelos interlocutores, possibilita vislumbrar as interseções deste com outras instâncias que estruturam os coletivos de pescas, tais como organização política, família e processos técnicos - para citar os três principais eixos aqui discutidos. Ao dedicar atenção às formas que o parentesco assume em coletivos pesqueiros potiguares, pretendo apresentar aos leitores as especificidades de suas relações, suas lógicas de funcionamento e os conflitos e tensões que ele enseja. O meu propósito aqui é analítico, partindo sempre das teorias nativas sobre o parentesco para alcançar e compreender as práticas e dispositivos sociais que ele engendra.

Aqui também faço a defesa de que o parentesco seja reconsiderado. Que lhe seja conferida pela Antropologia a importância dada a ele por muitos grupos e segmentos sociais "tradicionais" ou "complexos" contemporâneos. Cada vez mais grupos se pensam e constroem as suas identidades através do parentesco - na infinidade de formas que culturalmente este possa assumir. $\mathrm{O}$ fato é que o parentesco é atual e não se restringe a populações "tradicionais" - antes, equivocadamente chamadas de "primitivas" -, tal como pressupõem os primeiros estudos em Antropologia sobre o assunto (BESTARD, 1998). Também defendo - e aqui seguirei essa perspectiva - que as relações de parentesco sejam tomadas como construtos culturais que expressam relações sociais historicamente localizadas. E se mais tarde o arguto leitor se questionar o porquê de atrelar, em alguns momentos neste texto, a organização sociopolítica ao parentesco, à moda estrutural-funcionalista, explico que não se trata de uma escolha conceitual e/ou metodológica prévia, mas sim, uma teorização etnograficamente construída a partir da percepção nativa sobre o tema.

Os coletivos pesqueiros potiguares com os quais convivi, conferem ao parentesco o papel, entre outros, de mediador nas organizações produtivas e políticas. Por esse motivo analiso, neste artigo, os conflitos envolvendo as organizações políticas do coletivo pesqueiro de São Miguel do Gostoso, município do litoral norte potiguar. Nessa ocasião, volto minha atenção em especial para as duas formas de organização política que coexistem entre os pescadores artesanais de lá, que sem mecanismos conceituais mais elaborados, classifico a mais antiga como "tradicional" (mais afinada às relações de parentesco) e a outra - apropriando-me de certa linguagem weberiana - de organização burocrática (impessoal, ligada a outras instituições que regulam a prática pesqueira em diferentes níveis e onde os vínculos familiares são pouco levados em consideração, trata-se da Colônia de Pescadores Z-34). Meu interesse é perscrutar as duas organizações, fazendo emergir desta análise seus atores e suas relações, 
os conflitos frutos da coexistência, e sobretudo, o papel do parentesco nas suas configurações.

\title{
O PARENTESCO PESCADOR
}

\author{
O jangadeiro é filho de jangadeiro. Um por mil, não tendo a profissão \\ fixada na familia, escolhe a jangada para viver (Câmara Cascudo).
}

O primeiro investimento que gostaria de aqui fazer é seguir a proposta de Sahlins (2011) de tomar o parentesco enquanto um construto cultural sobre aos quais diferentes grupos se expressam e criam suas identidades. Tenho em mente o parentesco enquanto ordem classificatória, cujo conteúdo é construído e manipulado histórico, social e politicamente. Logo, não me interessa o que o parentesco é enquanto fato pré-discursivo, mas sim, as relações que ele representa para os grupos sociais que estudo.

\begin{abstract}
"In brief, the idea of kinship in question is 'mutuality of being': people who are intrinsic to one another's existence - thus 'mutual person(s)', 'life itself', 'intersubjective belonging'. I argue that 'mutuality of being' will cover the variety of ethnographically documented ways kinship is locally constituted, whether by procreation, social construction, or some combination of these. Moreover, it will apply equally to interpersonal kinship relations, whether 'consanguineal' or 'affinal', as well as to group arrangements of descent. Finally, 'mutuality of being' will logically motivate certain otherwise enigmatic effects of kinship bonds - of the kind often called 'mystical' - whereby what one person does or suffers also happens to others. Like the biblical sins of the father that descend on the sons, where being is mutual, then experience is more than individual" (SAHLINS, 2011, p. 2-3).
\end{abstract}

Embora mais a frente me detenha sobre um caso etnográfico específico, a experiência adquirida através de pesquisas empíricas com diferentes coletivos pesqueiros do litoral potiguar, bem como, a literatura existente sobre comunidades de pescas no Rio Grande do Norte, me permite a comparação - até pelos processos históricos de formação ser semelhantes - e considerações mais gerais sobre família e parentesco nesse universo social. Há poucas variações sobre estes temas e não será meu compromisso abordá-los neste artigo.

A primeira consideração que faço a respeito desta matéria é que no universo social da pesca potiguar, o parentesco é entendido como um conjunto de relações que envolvem a família - unidade constituída pela descendência fruto da união entre casais heterossexuais - e os vínculos construídos através da convivência e cooperação na prática pesqueira. Ou seja, os laços de consanguinidade são levados em consideração, mas não exclusivamente. Onde não há o compartilhamento da substância biogenética, relações de parentesco podem ser criadas tendo como referência uma identidade pescadora comum.

Na pesca artesanal - mais que na industrial - a organização produtiva está diretamente associada à família. É comum nesses coletivos que se referenciem como comunidade, como famílias socialmente localizadas e casamentos entre seus membros. Deste modo, não raramente, se imaginam e se tratam como primos, embora um olhar atento às genealogias das famílias revele que os tratamentos nem sempre implicam vínculos de sangue. Todavia, os grupos de trabalho, as composições das tripulações de cada barco levam sempre em consideração as distâncias dos vínculos, ou seja, muitos são parentes, mas nem todos são da família. Idealmente, pesca-se com familiares. 
Como detalharei a seguir, uma tripulação de pesca é idealmente formada por três ou quatro integrantes com funções bem definidas, são eles: Mestre, Proeiro e Ajudantes. Não raro, esses integrantes fazem parte de uma mesma unidade doméstica (pais, filhos, netos, sobrinhos). Embora predomine a homogeneidade econômica, os grupos de trabalho competem pelos recursos do mar em um complexo jogo que envolve alianças entre tripulações, blefes, trapaças, segredos e conflitos. A afirmativa do folclorista Câmara Cascudo (2002) - destacada no início deste tópico - é cada vez menos verificável, as novas gerações oriundas de famílias de pescadores não se interessam pelo ofício dos seus pais, tios e avôs. A pesca compete com novas modalidades de trabalho e a notória desvalorização da prática pela sociedade envolvente. A reprodução cultural do trabalho no mar, mais notadamente a modalidade artesanal, está comprometida. É nesse cenário que os processos de familiarização são cada vez mais frequentes. A incorporação do genro ao grupo de trabalho e a criação de vínculos através do apadrinhamento são exemplos disso.

O universo da pesca artesanal e industrial é marcado por forte assimetria entre os gêneros. As mulheres não participam da pesca em alto mar. Sua participação na economia familiar tende a ser reduzida pelos homens, desconsiderando o seu trabalho e denominando-o por ajuda, numa clara sinalização do seu caráter secundário e complementar. Sua circulação neste universo fica restrita por seus familiares do gênero masculino à esfera do doméstico, com raras exceções.

Já na pesca industrial, onde as jornadas de trabalho são mais longas que as da pesca artesanal, os vínculos de parentesco são estabelecidos levando em consideração a identidade operária comum e o tempo de permanência no mar. Não são raros os casos em que o homem arranja sua filha ou irmã para um de seus colegas, ou ainda, incorpora o amigo a sua família, tornando-o padrinho de um dos seus filhos ou ele próprio apadrinhando um dos filhos do companheiro de trabalho. Não é incomum ouvir relatos onde os vínculos estabelecidos com os companheiros de labuta assumiram a posição antes ocupada pela parentela consanguínea. Muito frequentemente os pescadores industriais se veem deixados por suas esposas e filhos ou serem tomados por um sentimento de estranheza e angústia com a família em virtude do pouco convívio que têm com eles.

\footnotetext{
“A gente quando sai de casa (para um cruzeiro de pesca), a gente tá quase se acostumando. Só que a gente nunca se acostuma mesmo, porque quando tá quase lá, a agente precisa voltar para o mar. A gente chega a passar até 20 dias na embarcação. No começo estranha, mas depois a gente se sente mais em casa no barco do que na casa de verdade. Então a gente se vê como família, trabalhando junto, comendo junto, dormindo junto. Tem colega aqui que quando voltou um dia pra casa, a mulher e os filhos tinham ido embora, a mulher já tinha até arrumado outro. Então, tu imagina, para esse cara, essa família aqui é tudo" (Arnaldo1pescador industrial. Natal, 5/2017).
}

Pelo exposto, pode-se concluir que o parentesco entre coletivos de pesca artesanais e industriais guardam, grosso modo, singularidade quanto a sua constituição. Ambos levam em consideração os laços consanguíneos, mas não exclusivamente. A relação com o trabalho, a identidade construída através dela, pode suscitar a criação de vínculos de parentesco que não são biológicos.

\section{TÉCNICA, POLÍTICA E PARENTESCO}

Como recorte representativo deste universo social que trato, a partir de agora analiso as relações entre técnica, política e parentesco no coletivo pes- 
queiro de São Miguel do Gostoso. A localidade existe desde 1884, quando foi fundada a vila de pescadores, mas a memória social é ainda anterior a essa data, o que me leva acreditar que a prática da pesca artesanal ${ }^{2}$ na localidade também seja mais antiga. De qualquer forma, como bem sinaliza Fortes \& Pritchard (1981, p. 36-37): "os modos de vida, juntamente com as condições ambientais, que impõem sempre limites autênticos aos modos de vida, determinam os valores dominantes dos povos e influenciam fortemente as suas organizações sociais, incluindo os seus sistemas políticos". Dou fé da aplicabilidade desta afirmação no caso aqui abordado. Como mostrarei no decorrer deste artigo, a organização produtiva na atividade pesqueira é determinada pelos vínculos de parentesco, que por sua vez, influenciam em larga escala as suas organizações políticas.

São Miguel do Gostoso possui um coletivo de pescadores artesanais de tanta expressividade que o município hoje deve a ele a sua origem no final do século XIX, enquanto vila de pescadores. Apesar das grandes mudanças atravessadas, principalmente nas últimas duas décadas, proporcionadas em larga escala pela adoção de práticas turísticas na localidade, e apesar do declínio da atividade motivada pelo surgimento de novas possibilidades de trabalho e da falta de investimento público, a pesca artesanal ainda é de grande importância para economia e cultura local (ALMEIDA FILHO, 2014).

A localidade possui 500 pescadores artesanais que praticam principalmente a pesca de linha, de rede e de espinhel, em jangadas ou barcos motorizados. Normalmente a tripulação é formada por três ou quatro homens, cada um deles cumpre uma importante função técnica. Ao Mestre cabe a função de orientar a organização produtiva, controlar a embarcação e encontrar o pesqueiro ${ }^{3}$. O Proeiro é responsável por lançar a rede, soltar o espinhel e após a captura, recolher o pescado. Os Ajudantes são geralmente rapazes em seus ritos de iniciação na pesca, seus corpos ainda não estão preparados para cumprir com destreza as funções do Proeiro ou a mestrança, mas sua função não é menor, eles ajudam a trazer o peixe capturado ao barco e organizam os apetrechos técnicos na ordem de uso.

A composição dos grupos de trabalho neste segmento social é totalmente mediada/orientada pelas relações de parentesco. A família é a unidade básica da pesca artesanal, sendo também a sua unidade política elementar. Trata-se de uma associação informal que opera no interior da sociedade envolvente, como esclarece Wolf (2003, p. 94): "notamos, portanto, que a estrutura formal de poder político e econômico existe em justaposição ou entremeada com vários outros tipos de estruturas informais que lhes são intersticiais, suplementares e paralelas".

Seguindo Wolf (2003), entendo que o coletivo aqui estudado, outrora, uma unidade corporada fechada, hoje, mais se assemelha às coalizões centradas no indivíduo, pela descrição que faz destas o autor:

\footnotetext{
"Nas situações em que a terra e o trabalho se tornam mercadorias, tais coalizões corporadas de parentesco tende a perder seu monopólio sobre recursos e pessoal. O indivíduo é, ao invés, 'liberado' para entrar em coalizões individuais, com o objetivo de maximizar seus recursos tanto no campo econômico como no mercado matrimonial" (WOLF, 2003, p. 97-98).
}

Em grande medida, esta transição se deve às mudanças sociais experimentadas pela comunidade local nas últimas décadas, mediante o processo de turistificação do município, onde, entre tantas mudanças, destaca-se o processo de mercantilização da terra e a redefinição das relações de parentesco e, em consequência, da composição dos grupos de trabalho (ALMEIDA FILHO, 2014). 
Todavia é natural em um grupo onde a maioria das pessoas se vê como parentes, que a unidade familiar permaneça revestida de importância. O que justifica Wolf:

"Eficiente ao máximo e com o mínimo de custo, a família é também, portanto, extremamente adaptável às mudanças nas circunstâncias que definem e circunscrevem sua existência. (...) Aqui podemos também sublinhar o fato de que, nesse atendimento a múltiplos objetivos, a família retém sua condição de organização multipropósitos por excelência em sociedades cada vez mais segmentadas em instituições dedicadas a um único objetivo" (WOLF, 2003, p. 100).

Não sem razão que, frente ao desinteresse dos mais jovens pelo oficio de seus parentes, a pesca artesanal tenha redefinido as relações de parentesco, admitindo para a composição dos grupos de trabalho os cunhados, genros e enteados, ou ainda, os compadres - geralmente vizinhos próximos absorvidos à família através do apadrinhamento.

“Aqui a maioria é família, sabe? Antes a gente só pescava com os da família, mas hoje está um pouco mudado, como tem menos gente para pescar, a gente pesca com quem tem" (Francisco - pescador. São Miguel do Gostoso, 09/2013).

Wolf (2003), ao analisar os tipos de amizades na América Latina, chamou de amizade instrumental o que, neste caso, chamo de compadrio. No grupo aqui abordado, a relação garante vantagens aos indivíduos envolvidos para além da atividade produtiva pesqueira, o que acaba por ampliar os centros de influências de uma determinada família ou grupo:

“[...] Pode ser que não se tenha estabelecido uma relação de amizade instrumental com o objetivo de obter acesso a recursos - naturais e sociais - mas o empenho por esse acesso torna-se vital nessa relação. Em contraste com a amizade emocional, que restringe a relação à díade envolvida, na amizade instrumental cada membro da díade age como uma ligação potencial com outras pessoas fora da díade. Cada participante apadrinha o outro. Em contraste com a amizade emocional, associada à limitação do círculo social, a amizade instrumental vai além das fronteiras dos grupos existentes e procura estabelecer pontas de lança em novos grupos" (WOLF, 2003, p. 104-105).

Na pesca artesanal as relações são fortemente baseadas na circulação de dádivas (MAUSS, 2003). Dar, receber e retribuir orientam a organização produtiva e política. Um bom exemplo disso é a relação entre pescadores e atravessadores. Nessa modalidade de pesca, onde o pescador é proprietário dos meios de produção e possui autonomia sobre os resultados do seu labor, a figura do Atravessador cumpre função importante na comercialização do pescado aos mercados inacessíveis aos pescadores. O atravessador também atua como um financiador na compra dos suprimentos necessários para a manutenção da pesca e provê os pescadores e seus familiares quando acometidos por moléstia.

Nas primeiras produções etnográficas sobre populações pescadoras, o atravessador aparece nas narrativas como um ator que se aproveita da fragilidade econômica dos pescadores, fornecendo-lhes o que o poder público lhes nega, e criando uma relação espoliativa sustentada por uma dívida moral, já que a honra e a gratidão são extremamente valorizados nesse segmento social. Todavia é preciso atentar-se às resistências e estratégias onde a maioria só enxerga submissão. A aliança entre pescadores e atravessadores através de casamentos ou do apadrinhamento de crianças, confere vantagens às famílias pescadoras envolvidas. 
A cegueira dessas primeiras produções frente às estratégias políticas das populações pescadoras deve-se ao fato de enxergarem os coletivos de pesca artesanais como comunidades tradicionais - no sentido estagnado do termo homogêneas e altamente orientadas por relações de solidariedade entre as famílias. As primeiras produções antropológicas neste campo excluem ou tomam como irrelevante a competição e os conflitos entre as famílias e as corporações produtivas. Nesse universo, a disputa pelos recursos do mar sugere tensões cuja formação leva em consideração as distâncias entre os vínculos de parentesco. Fator observado por Marques (2002) a respeito das famílias por ela estudada:

\begin{abstract}
"Com um pouco mais de tempo, o forasteiro perceberá que distâncias sociais e morais são anunciadas nas narrativas, insinuando-se através de um quadro de inclusões e exclusões formulado por cada narrador e concernente aos participantes da briga (ou das diferentes questões que a compõem), a si mesmo e a outros expectadores" (MARQUES, 2002, p. 427).
\end{abstract}

Embora muitas vezes os indivíduos se vejam como primos e parte de uma grande família, os grupos produtivos se estabelecem através da reunião de parentes próximos (avô, pai, irmãos, tios) considerados de uma mesma família. Com a reprodução social da pesca afetada pela concorrência com fatores exógenos, estratégias de familiarização, ou seja, de incorporação ao grupo familiar são cada vez mais frequentes. Assim, tem-se visto grupos de trabalho ou tripulações integradas por sujeitos que antes não eram considerados da família, ou na expressão nativa, próximos. O processo de familiarização na pesca potiguar é um mecanismo social de aproximação de vínculos de parentesco (quando os primos distantes se tornam genros, sogros e enteados) ou da criação de um vínculo onde antes não existia (o compartilhamento de responsabilidades morais com crianças através do apadrinhamento).

\title{
ENTRE A ASSOCIAÇÃO E A COLÔNIA
}

A partir deste ponto tratarei sobre o local do parentesco no conflito envolvendo as organizações políticas pesqueiras de São Miguel do Gostoso. Para tanto, é necessário antes de tudo explicá-las em suas origens. Há duas organizações que, em tese, representam a população pesqueira local: a Associação de pescadores e a Colônia de pescadores Z-34 (CPZ-34). A primeira foi criada em contraposição à segunda. A Associação está mais afinada aos arranjos familiares e políticos seculares. Enquanto a CPZ-34 trata-se de uma instituição ligada ao Estado nacional cujo objetivo é gerir o segmento pescador ${ }^{4}$.

A organização política tradicional é fortemente orientada pelas relações de parentesco e tem na figura do Mestre a sua principal liderança. Nessa modalidade de pesca, saber jogar com o peixe é essencial. Aqueles que se mostram competentes na execução técnica adquirem prestígio em seu coletivo, um elemento central na organização política tradicional, diretamente associado ao carisma que torna o Mestre um líder frente aos seus pares. A pesca artesanal é uma atividade honorífica e hierarquizada, não em classes, segmentos ou estamentos, mas em prestígio. Não garante à sua liderança distinção em rendimentos. No geral, o contrário: é comum que exista uma homogeneidade econômica. Dessa forma, não há entre os pescadores figura mais prestigiada do que o Mestre, ele em alguma fase de sua trajetória na pesca se mostrou apto a receber de um Mestre mais velho o segredo da marcação ${ }^{6}$. Os Mestres cumprem a função de mediação entre os grupos de trabalho em conflitos e conduzem a tomadas de decisões coletivas, todavia sua liderança não é dotada de poder coercitivo. Os Mestres são respeitados e ouvidos, mas o poder circula nesse segmento de forma 
horizontal. Embora organizem o segmento para a tomada de decisões, eles não estão autorizados a decidir pelo grupo.

Enquanto isso, por sua natureza impessoal, as Colônias de pescadores possuem uma estrutura burocratizada, um centro de poder exógeno baseado em hierarquias ascendentes ${ }^{7}$. As decisões que afetam as comunidades locais são tomadas fora delas e chegam a elas como imposições, sendo a principal delas a obrigatoriedade de filiação do pescador a Colônia de pesca para que tenha licença ao uso do mar e acesso às seguridades sociais8.

As tensões envolvendo a coexistência de formas de organizações tradicionais - no sentido temporal do termo - e instituições estatais com outras lógicas e dispositivos de funcionamento são comuns em outros cenários e segmentos sociais, como por exemplo, as populações camponesas. Comerford (2003), em sua etnografia sobre os conflitos políticos e religiosos no interior de Minas Gerais, também verificou conflitos de natureza semelhante ao que exponho, ao relatar sobre as relações entre os corrégos (orientadas por vínculos familiares) e comunidade (orientada por vínculos religiosos mais amplos). $\mathrm{O}$ que me sugere que o caso que trago - embora tenha suas particularidades - não seja um fenômeno isolado, mas partes de um conjunto de estratégias políticas e sociais de maior escala.

Segundo Foucault (2008), a substituição do modelo político baseado na família por um modelo de gestão baseado na população fez parte das estratégias de governança que surgiram a partir do século XVIII. Tal modelo, do qual o Estado brasileiro fez/faz amplo uso, reconhece na população características próprias, com efeitos econômicos passiveis de quantificação:

\begin{abstract}
"Pois qual pode ser o objetivo do governo? Não certamente governar, mas melhorar a sorte da população, aumentar sua riqueza, sua duração de vida, sua saúde, etc. E quais são os instrumentos que o governo utilizará para alcançar estes fins, que em certo sentido são imanentes à população? Campanhas, através das quais se age diretamente sobre a população, e técnicas que vão agir indiretamente sobre ela e que permitirão aumentar, sem que as pessoas se deem conta, a taxa de natalidade ou dirigir para uma determinada região ou para uma determinada atividade os fluxos de população, etc.” (FOUCAULT, 2008, p. 170).
\end{abstract}

No caso da pesca, o Estado brasileiro por meio de diferentes órgãos tem tentado converter os pescadores artesanais - cuja relação de trabalho é pautada na autonomia - em mão de obra para o segmento industrial, contrariando e dominando uma relação tradicional de trabalho e de organização política. $\mathrm{O}$ Estado nacional designa as Colônias de Pesca como instituições através da qual o segmento pescador deve dialogar com o poder público, no entanto, muito frequentemente, os coletivos de pescas não reconhecem as Colônias como órgão que representa os seus interesses, como é o caso da CPZ-34.

A Colônia de pescadores de São Miguel do Gostoso (CPZ-34) foi criada em 25 de setembro de 1995, por iniciativa de Jorge (vice-presidente da CPZ-34) e o Mestre Silvério. Segundo eles, o intuito era reunir o coletivo pesqueiro local para reivindicar ao poder público os seus direitos.

"Os pescadores são muito desunidos e a maioria analfabetos, não entendem de leis e nem de política, não sabem procurar os seus direitos. Foi por isto que a Colônia foi criada, antes eles se filiavam na de Touros (Colônia), mas havia muita má vontade do presidente de lá" (Jorge vice-presidente da CPZ-34. São Miguel do Gostoso, 02/2011). 
Na sua fundação, a CPZ-34 contava 116 pescadores filiados. Foi presidida por Jorge em três mandatos e, desde o seu afastamento para o exercício do mandato de vereador, tem sido presidida por Lúcia, esposa de Jorge. A sua sede está localizada na Avenida Enseada das Baleias na Praia do Maceió, a mesma propriedade onde reside o casal. Aqui vale uma consideração importante: embora a estrutura das Colônias pressuponha relações de impessoalidade, mesmo aqui os traços de uma organização política baseada em relações de parentesco estão presentes. Jorge, antes de ser presidente da CPZ-34, não tinha qualquer ligação com o coletivo local de pesca, exceto o fato de ter se casado duas vezes com mulheres cujas famílias possuem reconhecimento público neste segmento. A sua eleição como presidente talvez não tivesse ocorrido sem o apoio do Mestre Silvério, cujo prestígio emana de sua competência técnica e da relação secular de sua família com a pesca.

Inicialmente, a ideia de uma Colônia de pesca própria foi aceita por grande parte da população pesqueira local por enxergarem nisso a possibilidade de diminuir a burocracia no acesso às linhas de crédito, seguros e aposentadorias. Mas logo se viram inseridos em uma organização política que os submetiam ao cumprimento de regras que não compensava as vantagens de estar vinculado.

"Pescar não está compensando mais. A gente precisa de tanta coisa pra ter o direito de ir trabalhar sem correr o risco de ser pego e perder a licença pra pescar" (Francisco - pescador. São Miguel do Gostoso, 01/2014).

Além da obrigatoriedade da filiação para ter acesso aos direitos trabalhistas e até pra exercer a profissão, segundo os interlocutores, há também a fiscalização implacável de órgãos como a Marinha, IBAMA e IDEMA. Para eles fica clara a discrepância entre vantagens e desvantagens, o que, dessa forma, faz-lhes perceber a CPZ-34 como um órgão que, ao invés de amparar e defender seus interesses, cumpre função oposta.

Além disso, após desavenças entre o Mestre Silvério e o Jorge, que resultou na saída do primeiro da gestão da Colônia, um grande número de pescadores o seguiu e juntos criaram a Associação de Pescadores de São Miguel do Gostoso.

"O sonho da gente era uma cooperativa para fornecer o material que a gente precisa, representar a gente no governo e que permitisse a gente vender o peixe fora daqui e se livrar dos atravessadores. Aí eu e os pescadores que saíram de lá (CPZ-34) resolvemos criar a Associação, porque ela ia nos levar à cooperativa. Mas aí as burocracias são grandes e não deu certo" (Silvério. - Mestre de Pesca. São Miguel do Gostoso, 09/2013).

A Associação ainda existe, no ano de 2011 - momento em que o dado foi coletado - contava com apenas 48 associados. É presidida por Fernandes, funcionário público, filho de pescadores, mas que não é pescador. Ser associado garante apenas a vantagem de adquirir o gelo - necessário para a conservação do pescado na embarcação - por um preço mais acessível, já que a Associação possui uma pequena fábrica de gelo.

Após alguns anos de funcionamento da Associação, o Mestre Silvério, que foi o seu primeiro presidente, também acabou deixando a sua administração sob alegação do desconhecimento das leis e da morosidade burocrática dos processos. Embora inicialmente estivesse mais ajustada ao modelo de organização política tradicional, a Associação se mostrou ineficaz no diálogo com o poder público. No geral, os pescadores também se sentem insatisfeitos com 
a administração atual da Associação, mas não contestam tão enfaticamente o presidente em consideração ao pai dele, um famoso Mestre de pesca.

O desligamento de muitos pescadores da CPZ-34 em parte se devia ao reconhecimento de Silvério como liderança tradicional - jamais por uma exigência do mesmo, visto que, o mesmo não possui poder coercitivo sobre os pares, e prova disto é que muitos pescadores seguiram filiados -, mas também por não reconhecerem Jorge como apto a representar a categoria, uma vez que o mesmo não tem formação na pesca.

Os valores e moralidades presentes na organização política tradicional atua fortemente para a aceitação ou não de alguém como liderança. É considerável que, apesar de jamais poder exigir nada dos seus companheiros, o Mestre Silvério tenha conseguido apoio para a criação da CPZ-34 e, posteriormente, a Associação, através do prestígio construído na pesca. O modelo de organização tradicional, pautado na família, faz com que Fernandes - que assim como Jorge, não é pescador - sofra menos retaliações que o segundo, em virtude da longa tradição na pesca que sua família possui.

Após a saída de Silvério da administração da CPZ-34, Jorge parece, do ponto de vista nativo, antropomorfizar a instituição. Sua função é fazer cumprir o estatuto, convocar reuniões, contratar, demitir, indicar sócios e diretores, estabelecer convênios (SANTOS, 2015). A estrutura burocrática da CPZ-34 permite que Jorge seja naquele contexto a autoridade estatal, ou seja, a capilarização do poder público na localidade.

"Ele (Jorge) faz da Colônia a casa dele, aliás, a Colônia é na casa dele, ele faz gato e sapato. Não venham me dizer que ele busca benefícios para nós, os benefícios são para ele. A menina (Lúcia) é presidente, mas quem manda é ele" (Silvério - Mestre pescador. São Miguel do Gostoso, 09/2013).

Jorge é também o agente do Estado que promove o acesso aos direitos trabalhistas e políticas públicas que beneficiam a pesca. Seu monopólio sobre a CPZ-34 é possível graças ao seu conhecimento sobre leis, alianças políticas que extrapolam o segmento pesqueiro e o respeito conferido à família de Lúcia pelos pescadores locais. Aqui cabe uma nota importante: apesar dos desafetos conquistados por Jorge nos seus anos à frente da Colônia, Lúcia é sempre tratada com respeito e estima no discurso dos oponentes públicos, muitas vezes sendo alvo de pesares pela sua união com Jorge.

Em um segmento social onde a honra é categoria central sustentada pelo dever de retribuir o que se recebe, ao se valer de práticas clientelistas - onde se troca a agilidade nos processos de interesse do pescador por apoio político -, Jorge conseguiu se eleger vereador pelo município em 2004. Em 2008 ele tentou se reeleger, mas não obteve êxito. Tive notícias que a sua relação com os pescadores havia se desgastado de tal modo que estes vieram a boicotar sua candidatura.

"Eles se uniram contra mim, não votaram e eu perdi a eleição. Mas eu fiquei na minha, eles precisam de mim. Fico aqui sentado (aponta pra cadeira na frente da sua casa) esperando um a um vir pedir arrego" (Jorge-vice-presidente da CPZ-34. São Miguel do Gostoso, 02/2011).

Apesar de não reeleito, Jorge participou como secretário do Meio Ambiente na gestão municipal entre 2009 e 2012. Além de permanecer na gestão da CPZ-34 como vice-presidente. Para os interlocutores, Lúcia cumpre uma função figurativa, atuando mais como uma secretária do esposo do que de fato presidindo a Colônia. 
Atualmente a CPZ-34 conta com 500 pescadores associados e 300 aposentados. E apesar de não enxergarem a entidade como um órgão de classe ou representante do segmento, os pescadores permanecem filiados à CPZ-34 por uma imposição do Estado brasileiro que os impediria de exercer a pesca caso não fossem filiados. Além disso, enxergam na Colônia o único meio de acesso aos direitos trabalhistas, programas sociais e políticas públicas voltadas ao setor. A relação dos pescadores locais com a entidade é utilitarista, não a veem como defensora dos seus direitos nem como interessada em suas demandas. Já a Associação, apesar da reconhecida ineficiência no que diz respeitos aos propósitos iniciais de sua criação, ela continua ativa. Sua existência ajuda a reforçar a organização política tradicional pautada na corporação produtiva dos grupos familiares.

\section{CONCLUSÃO}

Foi proposta deste artigo abordar o parentesco enquanto símbolo que expressa uma gama de relações e como elemento sobre os quais os grupos por mim estudados constroem suas identidades na atividade pesqueira. Desta forma, demonstrei como ele é construído tomando como base o compartilhamento de vínculos de sangue, bem como, de uma identidade ligada ao trabalho. Parentesco é nesses contextos um vetor de socialidade mais amplo que inclui a família, que como mencionei, é pensada e elaborada através da diminuição da distância do vínculo.

Por fim, eu me propus a analisar como o parentesco está relacionado a outras instâncias da vida social pesqueira. E nesse ponto da discussão ele aparece altamente imbricado a formação e organização produtiva, bem como, as formas de organização política. Foi então que, dada a exemplaridade do caso, abordei o conflito de representação entre novas estratégias de administração pública (Colônia da Pesca) e as práticas políticas locais estabelecidas através das relações de trabalho e de parentesco. O conflito deve-se ao fato de instituições de natureza burocráticas, tais como a CPZ-34, instituírem uma estrutura baseada num sistema integrado de normas. Tal modelo de organização parece tentar subordinar saberes tradicionais e organizações políticas locais que lhes são anteriores. A vinculação do pescador à Colônia submete-o a um conjunto de leis, instaurando-se uma relação de poder que o modelo tradicional de organização política parece combater.

\section{NOTAS}

${ }^{1}$ A identidade de todos os interlocutores foi preservada, uma vez que grande parte das informações aqui expostas foram compartilhadas em nível de intimidade.

${ }^{2}$ Faz-se necessário explicar aos leitores pouco habituados com os povos do mar do que estou a falar quando uso o termo pesca artesanal. Seguindo uma expressiva produção antropológica sobre as populações marítimas, tem sido definida por artesanal toda pesca que: a organização produtiva seja mediada pelas relações de parentesco; que os indivíduos nela envolvidos participem de todas as etapas do processo produtivo; que suas embarcações sejam de pequeno porte; que seus apetrechos e técnicas sejam adaptados às especificidades ambientais locais; e finalmente, que seus conhecimentos sejam repassados através das gerações através da prática e da oralidade (DIEGUES, 1983; MALDONADO, 1986).

${ }^{3}$ Trata-se de espaços no mar onde as espécies marinhas se alimentam, reproduzem e descansam. Por consequência, segundo os pescadores, são regiões onde há peixes em abundância.

${ }^{4}$ No final do século XIX, dadas as más condições financeiras da Marinha, a instituição 
promoveu a nacionalização da pesca, efetivando o controle de toda a costa brasileira, justificando tal medida, em primeiro lugar, pela pretensão de desenvolvimento industrial; e em segundo, pela necessidade de defesa da costa. Entre 1919 e 1924, o Comandante da Marinha, Frederico Villar, percorreu a costa brasileira empreendendo a "Missão Cruzador", reunindo pescadores e organizando-os em Colônias de Pesca. Neste momento, as Colônias são entendidas como espaços de ampla influência política da Marinha. Para isso, a instituição considerou importante "civilizar" os homens do mar, trazendo o segmento à tutela do Estado, disciplinando a sua força de trabalho (RAMALHO, 2014).

${ }^{5}$ A relação manifesta em forma de jogo é orientada pelas noções de perícia técnica - o domínio cognitivo e corporal do conjunto de técnicas de pesca a serem usadas a depender do pescado que se pretende capturar - e moral-técnica - regra que consiste no uso de técnicas que não eliminem totalmente as possibilidades do pescado escapar. A expressão jogar com o peixe reflete a humanização destes seres, ou seja, o reconhecimento de que semelhantemente aos homens, os seres marinhos são sujeitos dotados de ação. O prestígio e reconhecimento do pescador junto ao seu agrupamento é resultado da sua competência neste jogo, ou seja, da sua competência em operacionalizar concomitantemente as duas noções citadas.

${ }^{6}$ Por complexas operações mentais que tomam com referencial os marcos naturais e sociais e a posição da embarcação no mar, o Mestre "marca" a posição do pesqueiro e o mantêm em segredo para que outras tripulações não usufruam de seus estoques.

${ }^{7}$ As Colônias de pesca estão inseridas em uma estrutura administrativa ascendente. Acima delas estão as Federações dos pescadores que administram as Colônias de pesca ligadas a ela em nível estadual. No topo da hierarquia, a Confederação Nacional da Pesca que administra as Federações (SANTOS, 2015).

${ }^{8}$ Em 1934, foi elaborado o Código de caça e pesca que previa, entre outras coisas, a entrega de relatórios mensais pelas Colônias ao departamento de caça e pesca. Além disto, o código exigia a filiação de todo pescador à Colônia de Pesca sob pena de serem proibidos de exercerem o ofício (RAMALHO, 2014).

\section{REFERÊNCIAS BIBLIOGRÁFICAS}

ALMEIDA FILHO, Paulo Gomes de. “Aqui se faz Gostoso”: uma etnografia do turismo em São Miguel do Gostoso (RN). Dissertação (Mestrado em Antropologia Social) - Centro de Ciências Humanas, Letras e Artes, Universidade Federal do Rio Grande do Norte, Natal-RN, 2014.

ALMEIDA, Mauro W. B. de. Lewis Morgan: 140 anos dos Sistemas de Consanguinidade e Afinidade da Família Humana (1871-2011). Cadernos de Campo, v. 19, n. 19, p. 309-322, 2012.

BESTARD, Joan. Parentesco y modernidad. Barcelona: Paidós. Introdução e primeiro capítulo, 1998.

CASCUDO, Luís da Câmara. Jangada: uma pesquisa etnográfica. 2. ed. São Paulo: Global, 2002.

COMERFORD, John. Como uma família: Sociabilidade, territórios de parentesco e sindicalismo rural. Rio de Janeiro: Relume-Dumará/NuAP-Coleção Antropologia da Política, 2003.

DIEGUES, Antônio Carlos. Pescadores, Camponeses e Trabalhadores do Mar, São Paulo, Ática, 1983.

FORTES, Meyer e EVANS-PRITCHARD, E. E. Introdução. In: FORTES, 126 Meyer e EVANS-PRITCHARD, E. E. Sistemas Políticos Africanos. Lisboa: Fundação Calouste Gulbenkian, 1981.

FOUCAULT, Michel. Microfísica do Poder. Rio de Janeiro: Graal, 2008.

MALDONADO, Simone. Pescadores do Mar, São Paulo, Ática, 1986.

MARQUES, Ana Claudia. Política e questão de família. Rev. Antropol. São Paulo v. 45, n. 2, p. 417-442, 2002. 
MAUSS, Marcel. Ensaio sobre a dádiva. In: Sociologia e Antropologia. São Paulo: Cosacnaify, 2003.

RAMALHO. Cristiano Wellington Noberto Ramalho. Pescadores, Estado e Desenvolvimento Nacional: da Reserva Naval à Aquícola. Revista RURIS. v. 8, n. 1. 2014.

SAHLINS, Marshall. What kinship is (part one). Journal of the Royal Anthropological Institute (N.S.) 17, p. 2-19. Royal Anthropological Institute, 2011.

SANTOS, Claudio Rogério dos. Investigando as interações sociais em São Miguel do Gostoso (RN): o caso da Colônia de Pesca Z-34 e os Pescadores Artesanais. Dissertação (Mestrado em Antropologia Social) - Centro de Ciências Humanas, Letras e Artes, Universidade Federal do Rio Grande do Norte, Natal-RN, 2015.

WOLF, Eric. Aspectos das relações de grupos em uma sociedade complexa: México; Parentesco, amizade e relações patrono-cliente em sociedades complexas. In: Antropologia e poder. Contribuições de Eric Wolf. Bela Feldman Bianco e Gustavo Lins Ribeiro (orgs.). Brasília: Editora da UnB; São Paulo: Imprensa Oficial; Campinas: Editora da Unicamp, 2003

WOORTMANN, Klaas. Reconsiderando o parentesco. Anuário Antropológico. Rio de Janeiro: Tempo Brasileiro, p. 149-186, 1977. 